time a grass-roots group has succeeded in bringing a case against a polluter in China. Friends of Nature and other green groups say that the pollution, which contains toxic chromium(VI), may have caused incidents of cancer in local villages. Bo says that the case "is a new initiative to allow pollution victims and entities like NGOs to bring cases to court against polluters". The plaintiffs are demanding that the company pays 10 million renminbi (US\$1.6 million) to a compensation fund to clean up the damage.

"There are still lots of issues to be worked out," Bo adds, "such as how to do environmental damage appraisals, and it is still not clear which parties are eligible to be plaintiffs." The court has held two meetings in the past two months to discuss the case, and Bo expects a ruling by the end of the year. "We are hoping this will set a precedent" for other NGOs and members of the public to bring similar cases, he says.

Alex Wang, an environmental lawyer at the University of California, Berkeley, says that the lawsuit signals an opportunity for civil-society groups to play a part in environmental enforcement. But "only time will tell whether this turns into precedent or remains a one-time event. Too many promising initiatives like this one have languished once the initial publicity has died down," he warns.

Green groups are also calling for improvements in the environmental impact assessments (EIAs) that companies must conduct before projects are given permission to go ahead. The public has 14 days to submit concerns and objections to proposed projects in China, but locals rarely have access to detailed plans and EIAs before it is too late, says Ailun Yang, who analyses emerging economies at the World Resources Institute, a think tank in Washington DC.

Yang says that companies should be required to disclose detailed information about the technologies to be used in projects, and to explain how they will dispose of waste. The government should also produce guidance for the public to make it easier for people to participate, she adds.

Keping Ma, a plant ecologist at the Institute of Botany, part of the Chinese Academy of Sciences in Beijing, says that China's central government is developing a "more positive attitude" towards ecological and environmental issues. And local officials did act quickly to cancel the projects in Qidong and Shifang, he points out.

But the strongest pressure for reform comes directly from members of the public, who feel that their lives are threatened by pollution and environmental damage, says Bo. "Throughout several dynasties, China has a history of villages rising up and overthrowing regimes they could not tolerate," he says. "I hope history does not repeat itself, because this has a high cost." -

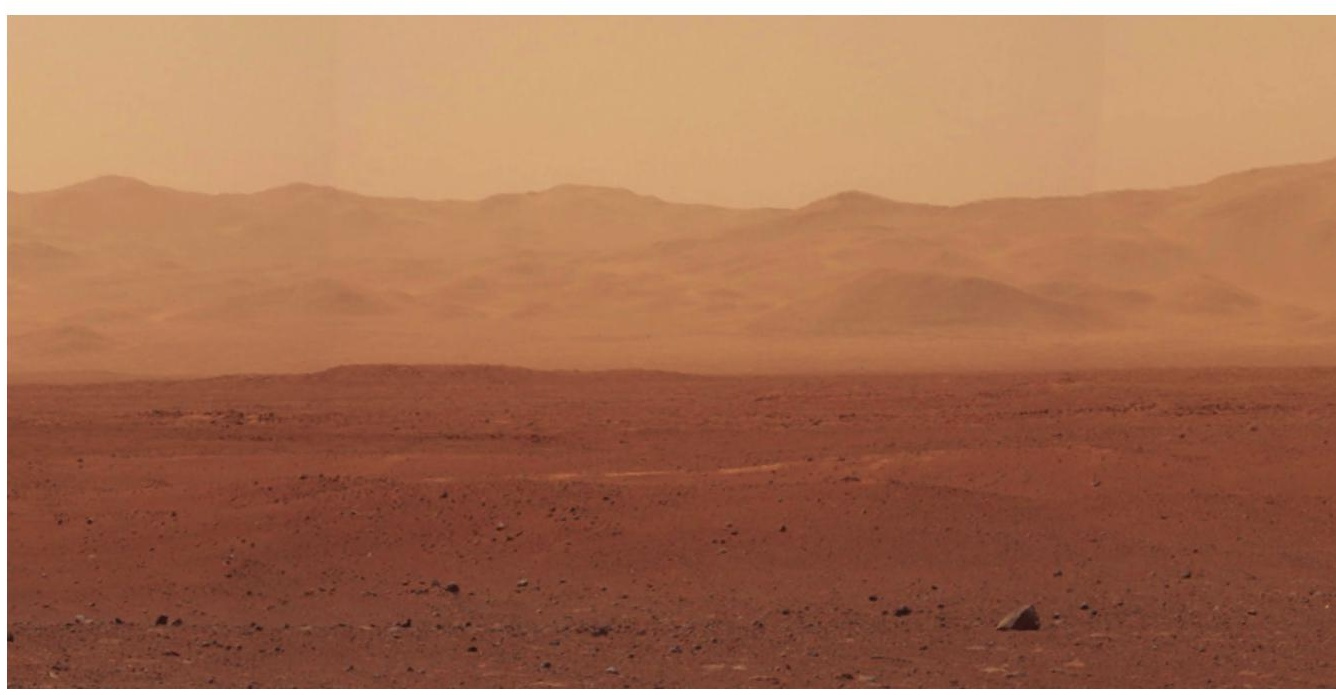

PLANETARY SCIENCE

\title{
Mars scientists await feast of data
}

\section{As the Curiosity rover prepares to take its first trip across the surface, the lead scientist shares his hopes for the mission.}

\section{BY ERIC HAND}

$\mathrm{J}^{2}$ ohn Grotzinger folds his rangy frame into a plastic leather booth at Conrad's, an unassuming diner in Pasadena, California. It is nearly midnight, and a smattering of customers have drifted in for a late-night snack. In the booth on one side, members of a Neil Young tribute band relax after a gig; on the other, a personal-trainer-cum-actor is winding down from a script reading.

But Grotzinger, who is chief scientist for NASA's Mars Science Laboratory mission, is trying to gear up for the start of his working day at the nearby Jet Propulsion Laboratory, as the rover Curiosity begins its fourth Martian day. Still riding the high of the rover's triumphant landing on 6 August, Grotzinger says that he is "overjoyed" with the landing site, a level plain between the rim of Gale Crater and Aeolis Mons, the imposing mountain at the crater's centre. But he is sobered by the demands of managing such a complicated machine and the 400-strong science team behind it. "I feel the burden of two-and-a-half billion dollars," says Grotzinger, a geologist at the California Institute of Technology in Pasadena. "I feel the burden of the future of Mars exploration."

Grotzinger's job is to get the maximum scientific pay-off from that investment

during the two years or more that the rover is expected to remain active. His day will begin at 12:42 a.m. with a science discussion with the principal investigators for the rover's ten instruments. But first Grotzinger needs breakfast and some coffee. One cup will do: the excitement of new data, which are expected in a downlink in two hours' time, will be enough to keep him alert.

Grotzinger was a regular at Conrad's in 2004, before and after his working days on the rover Opportunity, which landed that year along with Spirit, its twin, comprising the Mars Exploration Rover mission. Because the rovers were positioned on opposite sides of Mars, one team would be having breakfast while the other would be eating dinner. "The waitresses were always confused," he recalls. This time there is only one rover, but still no standard working day. Adapting to 'Mars time' requires starting each Earth day 40 minutes later than the last to match Martian daylight, inducing a state of perpetual jet lag.

Grotzinger is already marshalling different opinions on where the rover should go for its inaugural drive, expected to take place in

$\rightarrow$ NATURE.COM

For more on

Curiosity, see: nature.com/curiosity the next week. The first images from the rover's navigation cameras suggested one possibility when they revealed 
The first high-resolution colour panorama from Curiosity's mast camera reveals the distant rim of Gale Crater.

whitish linear features in a shallow trench scoured out by the blast of the landing system's retrorockets. The lines could be fractures filled with water-altered minerals - key targets for exploration in the mission's goal of assessing whether ancient Mars could have supported life. "We want to find out if we've got a bird in the bush right there," Grotzinger says.

Several hundred metres away is a second option for exploration: a five-metre-high slope, or scarp, that separates the dusty desert pavement on which the rover landed from the more hummocky terrain that lies beyond. The scarp marks the edge of materials deposited at the foot of an alluvial fan, a sedimentary feature left behind from floods that once spilled down from the rim of Gale Crater. The materials seem to be cemented or consolidated in some way, and layers exposed on the scarp might reveal the comings and goings of an ancient lake.

Away in the distance is the rover's ultimate destination: the 5.5-kilometrehigh Aeolis Mons, dubbed Mount Sharp by the science team, which casts a long shadow over the rover each morning. Data from orbiting spacecraft suggest that deposits on the mountain's lower shoulders were formed in water - and for now at least, these deposits represent the team's best chance of working out whether microbes could have lived on Mars billions of years ago.

Managing the tension between short-term and long-term goals will be a constant challenge for Grotzinger, says Raymond Arvidson, deputy principal investigator for the Spirit and Opportunity rovers and a planetary scientist at Washington University in St Louis, Missouri. "Do we stop and smell the roses or do we button up and continue to the next outcrop?"

Colleagues say that, in his geological field studies on Earth, Grotzinger balances both tendencies, displaying an exuberant fitness that carries him across wide terrain even as he keeps an eye on the minutiae of mineralogy and texture. He scrambles like a mountain goat, says Ralph Milliken, a former postdoctoral student of Grotzinger's and now a planetary scientist at Brown University in Providence, Rhode Island. Yet Andrew Knoll, a palaeontologist at Harvard University in Cambridge, Massachusetts, recalls a field trip with Grotzinger to Siberia in the early 1990s, during which the geologist discovered small pieces of volcanic breccia rock underfoot that had gone unnoticed by Knoll, no slouch of a

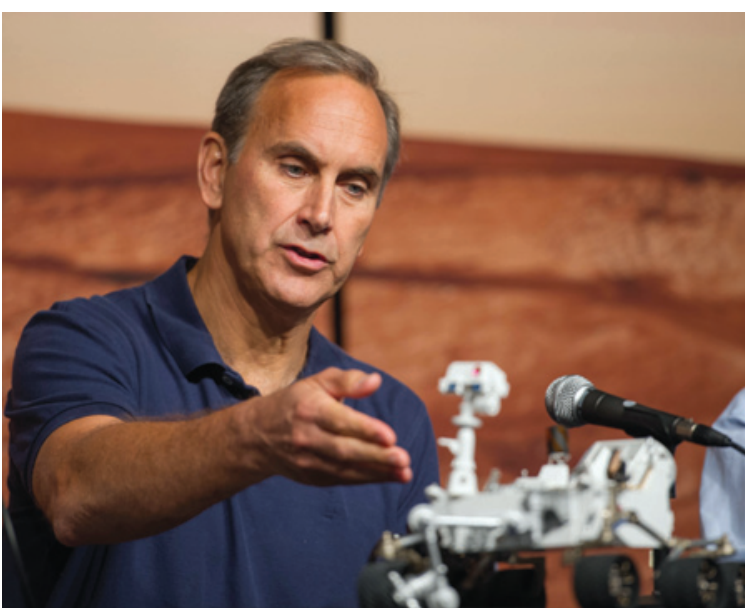

Geologist John Grotzinger is plotting a course for Curiosity.

field geologist himself. By dating those rocks, the researchers were able to pin down the timing of the Cambrian boundary better than ever before, and show that the Cambrian explosion of animal life happened incredibly quickly (S. A. Bowring et al. Science 261, 1293-1298; 1993).

Having an eye for detail and a gift for stratigraphic field work will certainly help Grotzinger to decode Mount Sharp and the millions of years of history that its layers represent. But he faces sociological challenges as well as scientific ones. Unlike Steven Squyres, the charismatic planetary geologist from Cornell University in Ithaca, New York, who was principal investigator for Spirit and Opportunity, Grotzinger does not have final authority over plans for the rover. Instead, as project scientist, he heads an executive committee that is made up of a representative from NASA headquarters and the principal investigators for the ten instruments. "He appreciates that he's the head of a committee, and not the Pope," says Knoll.

Arvidson says that Grotzinger is already aware of the job's limitations. "John's working the crowd," he says. "He really understands that in order to get buy-in, you have to establish trust."

One exercise that Grotzinger is proud of is a crowd-sourced geological map of Curiosity's landing ellipse that was put together before touchdown. Recognizing that little was known about the fine-grained detail of the location, he divided the ellipse into 151 quadrangles, measuring roughly 1.6 kilometres on each side, and asked for volunteers from the science team to turn orbiter data into geological maps of each sector. It was partly a team-building effort in the lead up to the landing - how better to bring opinionated geologists into the fold than by working on a patchwork quilt? But he also wanted to show the wider team that the landing terrain was full of intriguing detail that should not be overlooked in a fast trek to Mount Sharp.

"There is going to be something for everyone," says Grotzinger, slurping his coffee and smiling. "I quoted Bob Dylan when I was talking to these guys ... 'A lot of people don't have much food on their table. But they got a lot of forks 'n' knives. And they gotta cut somethin.' If you have an empty plate, people are going to go for each other. But if there's a wealth of riches, we can all share." - 